\title{
Editorial
}

J Periodontal Implant Sci 2010;40:209-210 • doi: 10.5051/jpis.2010.40.5.209

\section{Up in the air}

(C) sifting through them, and I think 'What the heck is this?'

11 and then it was 'Oh my god, oh my god, oh my god.' " Does it sound like a denunciation from the investigator of the Holocaust? To our dismay, these words are from Professor Susan M. Reverby of Wellesley College, who found unpublished records of inhumane medical research in the University of Pittsburgh archives and submitted a report on the experiments in Guatemala to this winter's issue of the Journal of Policy History. Before this exposure, she had already presented her findings about the dark history of modern medicine in January. However, it is deplorable that her presentation drew little attention. A former director of the Centers for Disease Control, Dr. David J. Sencer prompted the U.S. government to investigate this inexcusable research of our own time.

Nowadays, we know that the Nuremberg trials of Nazi doctors performing unethical experiments on the inhabitants of concentration camps led to various ethical guidelines. Among these, the Declaration of Helsinki, which was proposed in 1964 and in its revised form, is still regarded as the authoritative one in human research ethics. We are now living in an age where even animal ethics is appreciated. Taking this into consideration, we can't account for how long it took to expose this study. Do we really comprehend the core values of research ethics in medicine?

We should respect autonomy, which stands for the rights of individuals to self determination. Also, beneficence, which promotes the wellbeing of 
the patient, is fundamental to medical ethics. Primum non nocere, not to harm your subjects, is regarded even more important than to do them good. Justice deals with matters of fairness and equality, while dignity handles the issue of human rights. In my personal opinion, honesty, above all, should be the value that guides us in the present age. On reflection, it becomes evident that the lack of honesty was central to the Tuskegee study and Guatemalan experiment. That is why we can't overemphasize the value of informed consent. Of course, even this short list of values can conflict with each other in complicated real situations. But even if such ethical arguments could result in strong disagreement, we should never cease communicating our various perspectives, which secures a harmonized solution in the end.

While selecting the six original articles and one case report for this issue of JPIS, I came across the quote from Chinese premier Wen Jiabao in a recent interview with CNN, "The wish and will of the people are not stoppable. Those who go along with the trend will thrive, and those who go against it will fail." Although this is about the political prospect of his nation, it is also applicable to the aforementioned field, human research ethics. We scientists unendingly have the obligation to keep both eyes open.

\section{Tae-II Kim}

Editor

Department of Periodontology, Seoul National University School of Dentistry,

28 Yeongeon-dong, Jongno-gu, Seoul 110-749, Korea

E-mail: periopf@snu.ac.kr, Tel: +82-2-2072-2642, Fax: +82-2-744-1349 